Journal of Engineering and Applied Sciences 14 (4): 1226-1232, 2019

ISSN: 1816-949X

(C) Medwell Journals, 2019

\title{
Designing of Arrythmia Telemonitor Device Using Pulse Sensor Based on Web
}

\author{
R. Wahyu Kusuma, I. Ridha, E.P. Swelandiah and R. Yasman \\ Department of Electrical Engineering, Gunadarma University, Depok, Indonesia
}

\begin{abstract}
This research aims to design a prototype medical device that is expected to be applied for independent monitoring of the remote by the patient as well as to record medical data of cardiac arrhythmias. This research was conducted by using experimental model research with laboratory test. The arrhythmia telemonitor device that has been constructed is composed of pulse sensor, keypad and press switch as input block. Process block consisting of Arduino Mega Kit module, Ethernet Shield, router and USB Modem. The output block is composed of a $16 \times 2$ alpha numeric LCD viewer module and a web display accessed using a computer or smartphone device. Based on test results on five respondents obtained level of accuracy is based on the calculation of procentstase error average of $0.25 \%$. While the results of precision testing based on the calculation Standard deviation (Stdev) averaged 13.27.
\end{abstract}

Key words: Telemonitoring device, arrhythmia, web-based, pulse sensor, LCD, Ethernet Shield

\section{INTRODUCTION}

The heart is a human organ that has a vital function. Small abnormalities in heart organ can have a big effect on our body's performance. Based on data from the World Health Organization (WHO), heart disease has a $29 \%$ percentage of deaths in the world and 17 million people die each year from heart and blood vessel disease worldwide.

Detection of cardiac arrhythmias can be performed by a heart rhythmic recording device called Electrocardiography (ECG) (Tompkins and Webster, 1981).

In addition to $\mathrm{EKG}$, medical devices that have been used by medical teams to detect heart rate and rhythm are Electrophysiology Study (EPS) (Babiker et al., 2011) and Insertable Loop Recorder (ILR) (Jones, 2015). The problems that arise in addition to the expensive cost of procuring these tools, also require special abilities in operation, so, it can not be used independently by the patient.

Kusuma et al. (2016) and Sukoco has succeeded in building Arduino-based heart arrhythmia detector with optical sensor. However, it has not been designed to monitor arrhythmias remotely and can not record the results and timing of the examination.

Kohler et al. (2002) have reviewed and compared algorithms to detect QRS-complex signals using software. One of the simplest algorithms for QRS detection is presented by Tompkins and Webster (1981) in his book biomedical digital signal processing. The book describes QRS detection using band pass filtering technique, so that, the patient's heart rate is calculated every minute by calculating the R-R interval. The research have been studying equipment to easily acquire cardiorespiratory information at home using piezoelectric sensors (Igasaki and Kobayashi, 2017). The other research by Zhang et al. (2014) have been studying from radar life parameter monitoring system for respiration and heartbeat signal separation, therefore, the characteristic parameters of respiration, heartbeat could be extracted to provide the basis for family care and disease prevention. But the two researches have not yet applied to a web-based monitoring process.

The development of information and communication technology enables data of examination result of heart rate can be sent to doctor through communication device like smartphone or laptop through internet network. This allows a doctor to monitor heart health from the patients he or she is handling.

Based on the above problems, this research will design and build devices that can monitor long distance (telemonitor) cardiac arrhythmia using web-based applications through internet communication channels.

\section{MATERIALS AND METHODS}

Arrythmia premonitory: This type of arrhythmia indicates a condition that harmful to the health of the patient including: Premature Ventricular Contraction (PVC) interpolated PVC, bigeminy, trigeminy, R-on-T beat, Atrial Premature Beats (APB), skipped beat. There are several methods to determine the presence of cardiac rhythm disorders, there are: using direct

Corresponding Author: R. Wahyu Kusuma, Department of Electrical Engineering, Gunadarma University, Depok, Indonesia 


\begin{tabular}{|c|c|}
\hline Type of aritmia & Algorithm \\
\hline$\overline{\mathrm{PVC}}$ & $\mathrm{RR}_{\mathrm{t}-1}>0.9\left(\mathrm{AR}_{\mathrm{t}-2}\right), \mathrm{RR}_{\mathrm{t}-1}+\mathrm{RR}_{\mathrm{t}}=2\left(\mathrm{AR}_{\mathrm{t}-2}\right)$ \\
\hline R-on- $\mathrm{T}$ & $\mathrm{RR}_{\mathrm{t}-1}<0.33\left(\mathrm{AR}_{\mathrm{t}-2}\right), \mathrm{RR}_{\mathrm{t}-1}+\mathrm{RR}_{\mathrm{t}}=2\left(\mathrm{AR}_{\mathrm{t} \cdot 2}\right)$ \\
\hline Bigeminy & $\begin{array}{l}\mathrm{RR}_{\mathrm{t}-3}<0.9\left(\mathrm{AR}_{\mathrm{t}-4}\right), \mathrm{RR}_{\mathrm{t}-\mathrm{r}} 0.9(\mathrm{AR}) \mathrm{l} \cdot \mathrm{RR} \quad+\mathrm{RR} \quad \overline{\mathrm{T}} \\
2\left(\mathrm{AR}_{\mathrm{t}-4}\right), \mathrm{RR}_{\mathrm{t}-1}+\mathrm{RR}_{\mathrm{t}}=2\left(\mathrm{AR}_{\mathrm{t}-4}\right)\end{array}$ \\
\hline Trigeminy & $\begin{array}{l}\mathrm{RR}_{\mathrm{t}-2}<0.9\left(\mathrm{AR}_{\mathrm{t}-3}\right), \mathrm{RR}_{\mathrm{t}-1}<0.9\left(\mathrm{AR}_{\mathrm{t}-3}\right) \\
\mathrm{RR}_{\mathrm{t}-1}+\mathrm{RR}_{\mathrm{t}-1}+\mathrm{RR}_{\mathrm{t}}=2\left(\mathrm{AR}_{\mathrm{t}-3}\right)\end{array}$ \\
\hline Interpolated PVC & $\mathrm{RR}_{\mathrm{t}}-<0.9\left(\mathrm{AR}_{\mathrm{t}-2}\right), \mathrm{RR}_{\mathrm{t}-1}+\mathrm{RR}_{\mathrm{t}}=2\left(\mathrm{AR}_{\mathrm{t}-2}\right)$ \\
\hline
\end{tabular}

observation of study cardiogram. Arrhythmias can be diagnosed by the method of comparing the output signal with a variety of ECG arrhythmia signal images were then analyzed by using ANN (Artificial Neural Network). Using a mathematical model analysis of ECG signal output by the algorithm as shown in Table 1.

Table 1 shows a mathematical model that defines algorithms wide variety of arrhythmias were detected. There are two variables that are used are:

$\mathrm{RR}=$ One time interval R-R

$\mathrm{AR}=$ Average from interval $\mathrm{R}_{1}-\mathrm{R}$

$A R_{t}=$ Average of eight time interval $R_{1}-R_{9}$

$\mathrm{RR}_{\mathrm{t}}=$ Time interval $\mathrm{R}_{8}-\mathrm{R}_{9}$

$\mathrm{RR}_{\mathrm{t}-1}=$ Time interval $\mathrm{R}_{7}-\mathrm{R}_{8}$

$A R_{t-1}=$ Average of eight time interval $R_{1}-R_{8}$

Design of hardware : The design of this tool consists of several blocks of the series are arranged into a telemonitor device cardiac arrhythmia-based mobile communication as shown in Fig. 1.

Based on the block diagram shown in Fig. 1, the telemonitor arrangement of cardiac arrhythmias is suspended over the input blocks, process blocks and output blocks.

Input block: In the input block consists of 3 components of pulse sensor circuit, keyboard (keypad) $3 \times 4$ and push button (push button). Pulse sensor is a sensor that can detect heart rate based on blood flow. This sensor can be operated by attaching to the fingertips or ears. The schematic of the circuit and physical display is shown as Fig. 2.

Proses block: The process block is composed of 3 components of Arduino Kit module, Ethernet Shield Kit module and router device. The Arduino Mega 2560 module kit is used as a processing unit in the cardiac arrhythmia telemonitor device. Ethernet Shield W5100 module kit used for data communication function. Cardiac arrhythmia monitor results that have been processed by Arduino module, then the data is sent to the web server via. the internet using router device and USB Modem.

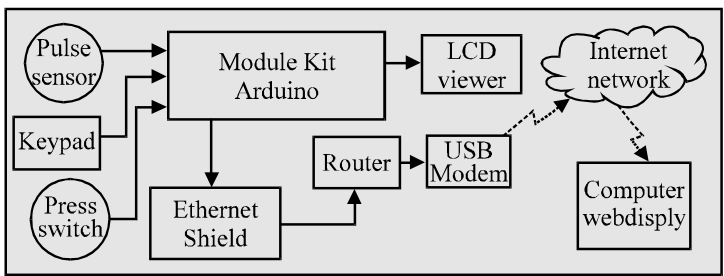

Fig. 1: Block diagram of telemonitor tool web-based heart Arrhythmias

Web views of monitoring results can be accessed using other devices such as notebooks or smartphones. Figure 3 show components needed in this device design.

Output block: The output blocks are composed of components consisting of LCD display kit module and web display as shown in Fig. 4-8.

Design of software: The design begins by defining the signal characteristics of the types of arrhythmias based on the Table 1 algorithm

In this program, there are two $\mathrm{RR}$ and $\mathrm{AR}$ variables. $R R$ is the $R-$ to- $R$ interval and the $A R$ is the average range of the given time interval. The subscript value is used as a time-related sign. $R_{t}$ means the last interval. $R_{t-1}$ means an interval R-to-R interval of seven of the eight sample periods. $\mathrm{AR}_{t}$ is the average time R-to- $\mathrm{R}$ of the eight sample intervals. $\mathrm{AR}_{\mathrm{t}-1}$ means that the mean time-to- $\mathrm{R}$ $\mathrm{R}$ seven intervals of eight intervals were sampled (Tompkins and Webster, 1981).

When the heartbeat peak signal is detected, the peak signal is marked as $\mathrm{R}$, the subscript is the numbered sequence of detected heartbeats. To process the arithmetic algorithm formula it is necessary to know the interval between $\mathrm{R}$-to- $\mathrm{R}$ and the period of each heartbeat. The value of $T 1$ from $R_{1}-R_{2}$, the value of $T 2$ from $R_{3}-R_{2}$ and continues through the period of eight.

Period is displayed before on the label program for RR. Subscript after RR stamped ordered period, $R_{t}$ is the period last period of last period of nine signals captured. $R_{t-1}$ is the period one before the last eight intervals are captured, continuing the first period $R_{t}$. .

The definition of AR is the average of each period based on the label on the subscript. $\mathrm{AR}_{t}$ is the average of eight captured intervals, the ART value is

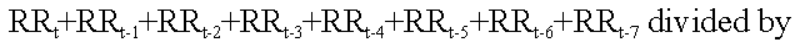
eight. $\mathrm{AR}_{\mathrm{t}-1}$ value is $\mathrm{RR}_{\mathrm{t}-1}+\mathrm{RR}_{\mathrm{t}-2}+\mathrm{RR}_{\mathrm{t}-\mathrm{t}}+\mathrm{RR}_{\mathrm{t}-\mathrm{A}}+\mathrm{RR}_{\mathrm{t} \cdot \mathrm{s}}+\mathrm{RR}_{\mathrm{t} \cdot \mathrm{6}}+$ $R_{t} \cdot 7$ divided by seven, continue to get $R_{t} \cdot 7$. Figure 9 shows flow chart of the arrhythmia detection process. 
(a)

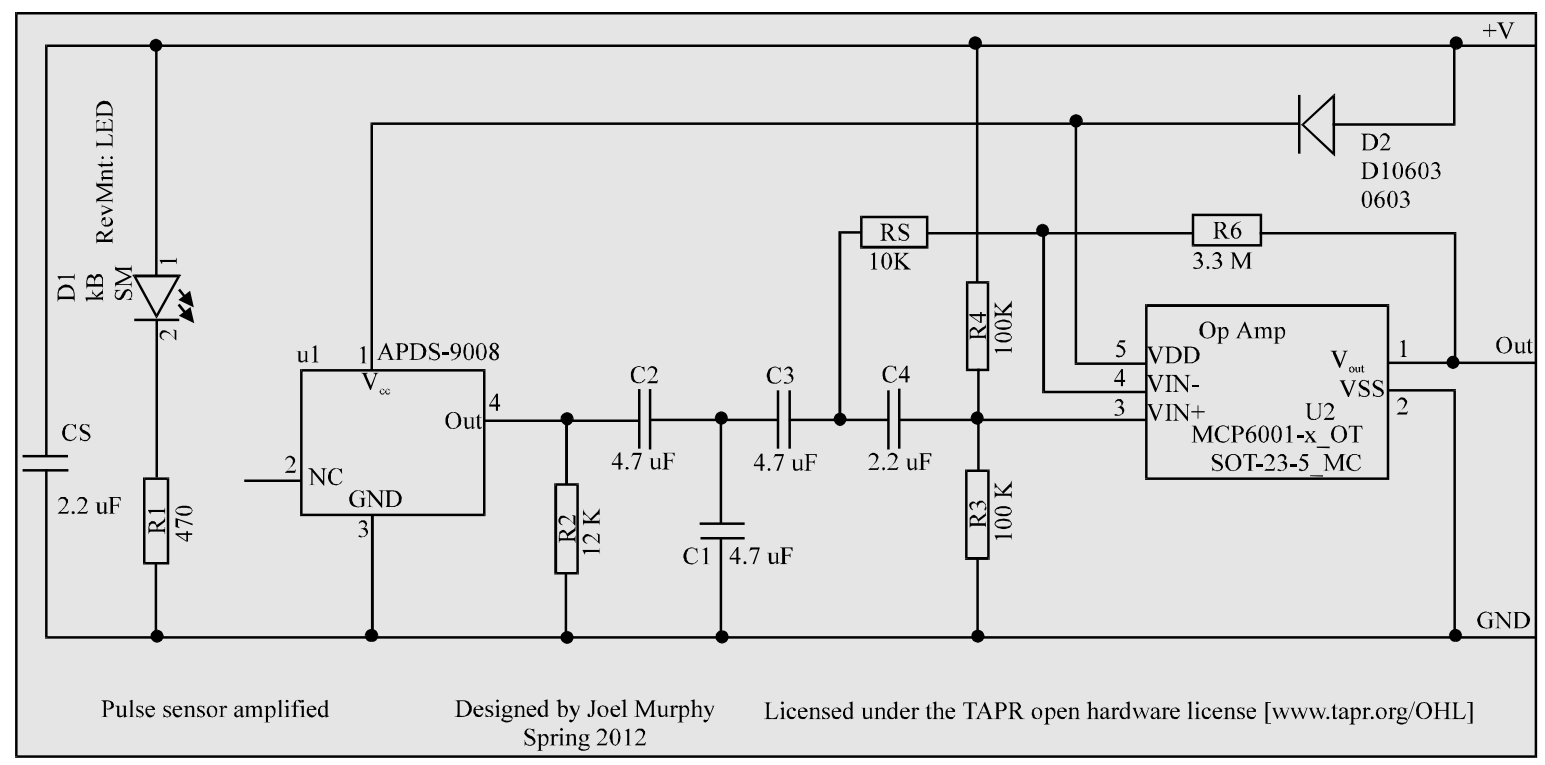

(b)

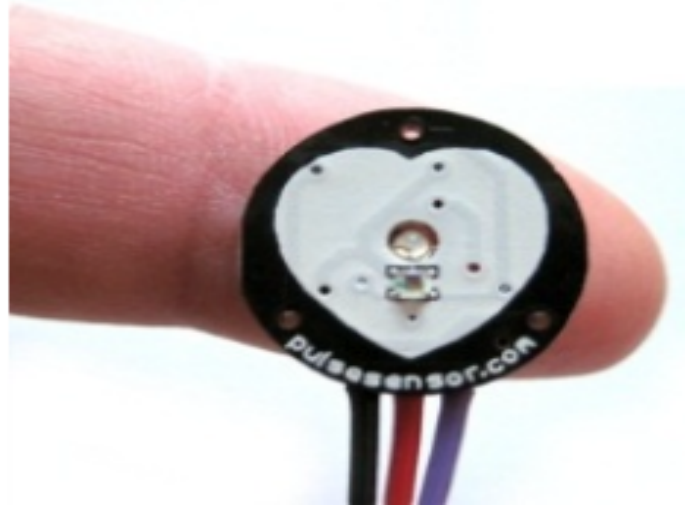

Fig. 2: a, b) Schematic and physical display of pulse sensor circuit

(a)

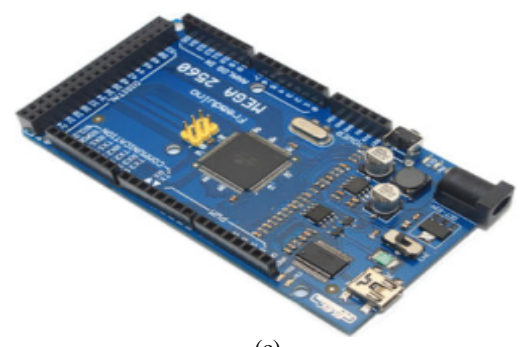

(b)

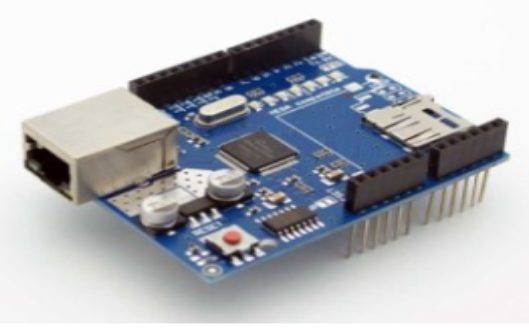

(c)

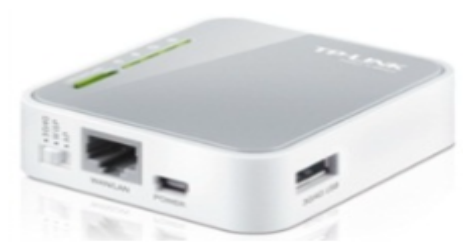

Fig. 3: a-c) Physical display of Arduino Mega 2560 module kit, Arduino Ethernet Shield W5100 and portable router 
(a)

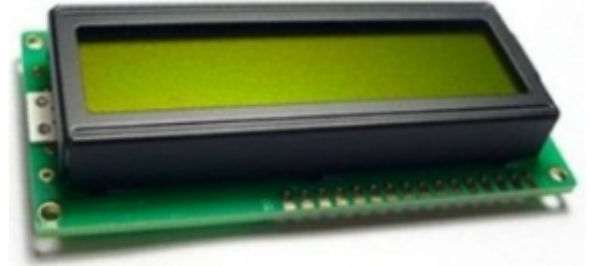

(b)

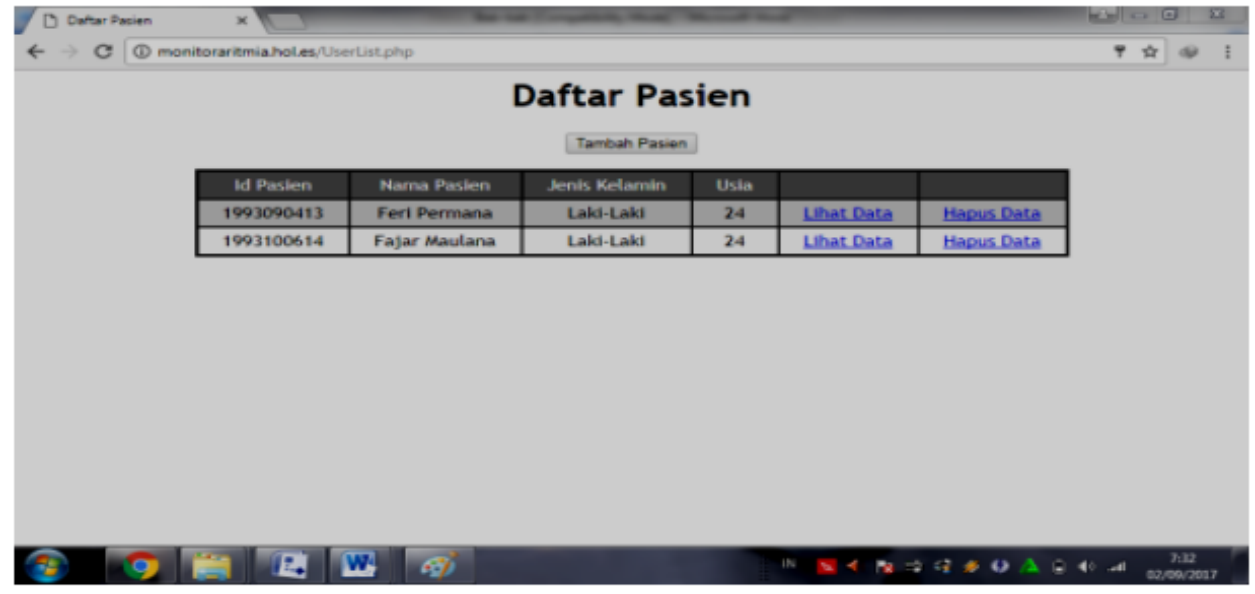

Fig. 4: Output block devices: a) LCD viewer and b) Web display

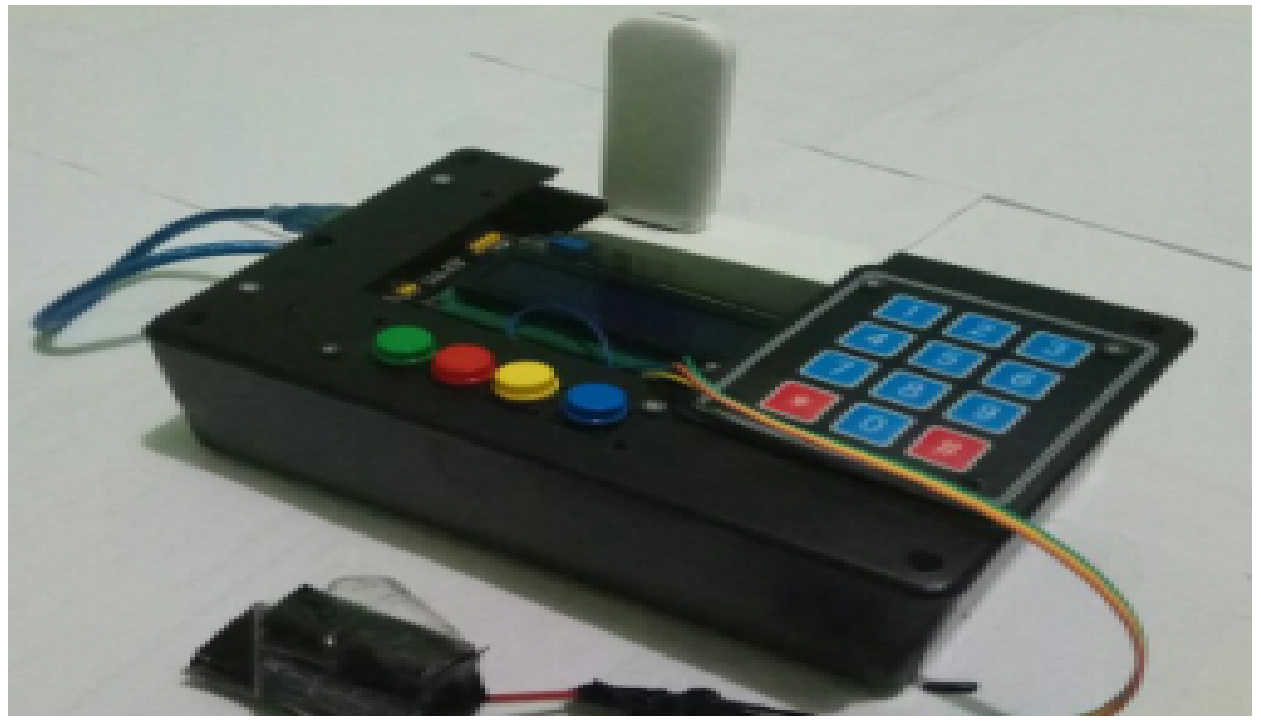

Fig. 5: Physical display of arrythmia telemonitoring device

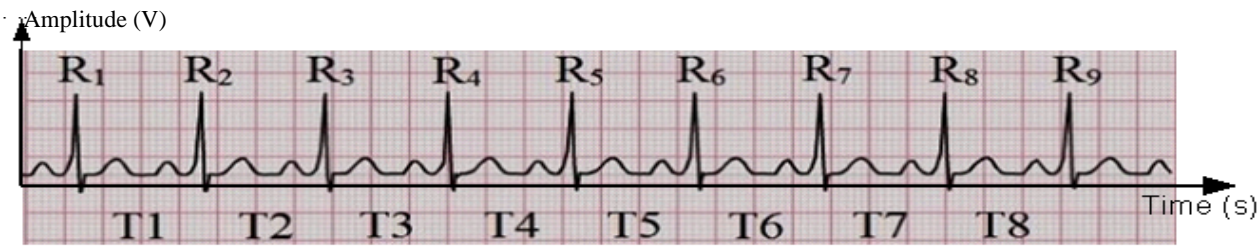

Fig. 6: $\mathrm{R}$ representation as the peak of the tick and $\mathrm{T}$ as the time period on the heartbeat signal 


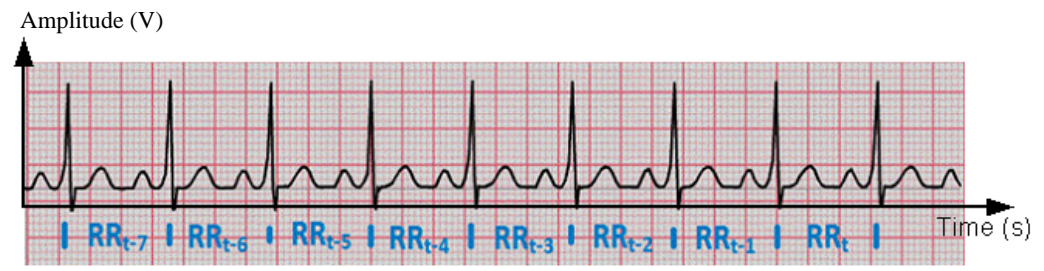

Fig. 7: Defining the time period of $\mathrm{RR}$

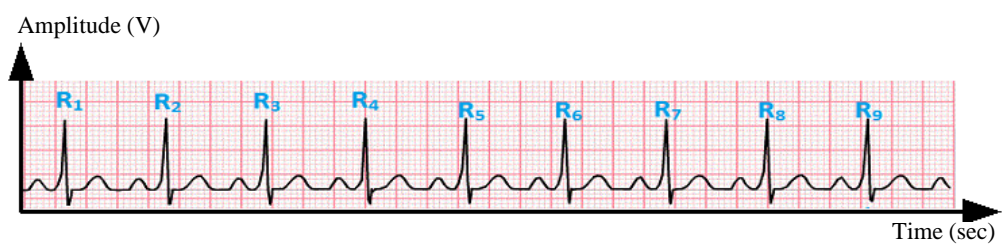

Fig. 8: Defining AR as the average time period
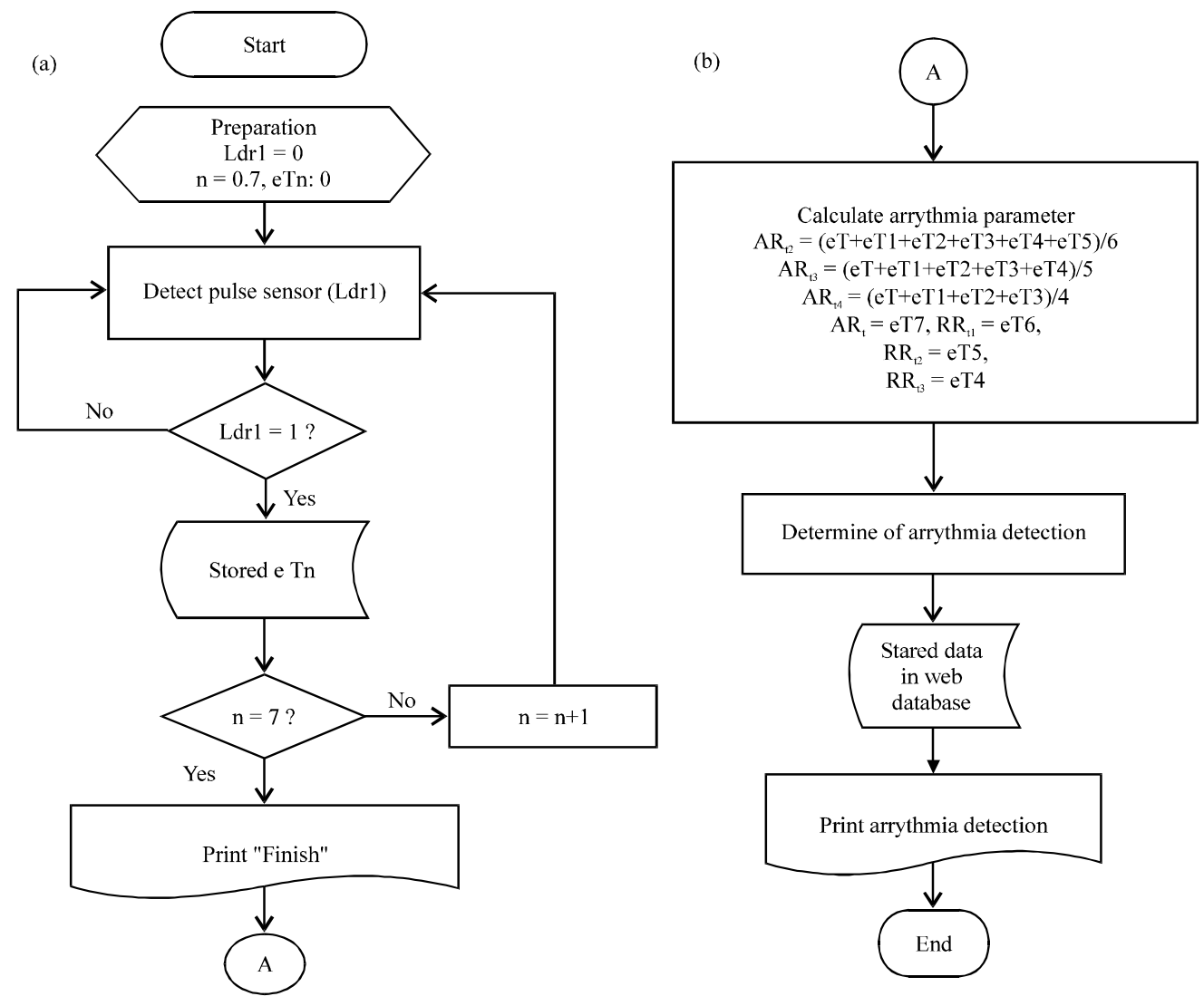

Fig. 9: a, b) Flow chart of the arrhythmia detection process

\section{RESULTS AND DISCUSSION}

Test of sensor block : Testing conducted to determine the success of the tool has been built. The test is performed on the output signal of the pulse sensor block. Figure 10 shows the signal display when the pulse sensor has not detected a heartbeat (stanby state). In this signal, shows the pulse sensor output, obtained the signal amplitude is around $10 \mathrm{mV}$ with a period that cannot be determined, so, it is said to be a noise signal. Figure 11 shows the signal display when the pulse sensor has detected a heartbeat. In this signal shows the pulse sensor output, obtained an amplitude value of $8.4 \mathrm{~V}$ with a period value of $800 \mathrm{msec}$ or frequency $1.25 \mathrm{~Hz}$. 
Table 2: Test result time interval $\mathrm{R}$ to $\mathrm{R}$ on the 1st respondent

\begin{tabular}{|c|c|c|c|c|c|c|c|}
\hline \multirow[b]{2}{*}{ Period (msec) } & \multicolumn{5}{|l|}{ Attempt } & \multirow[b]{2}{*}{ SD } & \multirow[b]{2}{*}{ Mean $(m s e c)$} \\
\hline & 1st (ND) & 2nd (ND) & $3 \mathrm{rd}(\mathrm{ND})$ & 4th (ND) & 5th (ND) & & \\
\hline $\mathrm{T} 1$ & 892 & 915 & 871 & 892 & 920 & 19.84 & 898.0 \\
\hline $\mathrm{T} 2$ & 907 & 880 & 889 & 903 & 887 & 11.37 & 893.2 \\
\hline $\mathrm{T} 3$ & 915 & 920 & 923 & 924 & 904 & 8.170 & 917.2 \\
\hline T4 & 923 & 890 & 901 & 895 & 924 & 15.92 & 906.6 \\
\hline T5 & 931 & 892 & 906 & 911 & 913 & 14.05 & 910.6 \\
\hline T6 & 905 & 896 & 898 & 903 & 907 & 4.660 & 901.8 \\
\hline $\mathrm{T} 7$ & 830 & 850 & 841 & 869 & 873 & 18.28 & 852.6 \\
\hline $\mathrm{T} 8$ & 796 & 821 & 786 & 807 & 792 & 13.83 & 800.4 \\
\hline
\end{tabular}

Result aritmia; "ND = Disease not Detection

Table 3: Testing results of tool accuracy

\begin{tabular}{|c|c|c|c|c|c|c|c|c|c|}
\hline \multirow[b]{2}{*}{ No. respondent } & \multicolumn{9}{|c|}{ Period (msec) } \\
\hline & Tool & $\mathrm{T} 1$ & $\mathrm{~T} 2$ & $\mathrm{~T} 3$ & $\mathrm{~T} 4$ & T5 & T6 & $\mathrm{T} 7$ & T8 \\
\hline \multirow[t]{3}{*}{$1 \mathrm{st}$} & ATD & 892 & 907 & 915 & 923 & 931 & 905 & 830 & 796 \\
\hline & Osc & 890 & 905 & 917 & 922 & 930 & 906 & 831 & 800 \\
\hline & $\% \mathrm{Er}$ & 0.22 & 0.22 & 0.22 & 0.11 & 0.11 & 0.11 & 0.12 & 0.50 \\
\hline \multirow[t]{3}{*}{ 2nd } & ATD & 915 & 880 & 920 & 890 & 892 & 896 & 850 & 821 \\
\hline & Osc & 914 & 881 & 921 & 891 & 895 & 899 & 852 & 820 \\
\hline & $\% \mathrm{Er}$ & 0.11 & 0.11 & 0.11 & 0.11 & 0.34 & 0.33 & 0.23 & 0.12 \\
\hline \multirow[t]{3}{*}{ 3rd } & ATD & 871 & 889 & 923 & 901 & 906 & 898 & 841 & 786 \\
\hline & Osc & 873 & 890 & 920 & 900 & 905 & 890 & 840 & 788 \\
\hline & $\% \mathrm{Er}$ & 0.23 & 0.11 & 0.33 & 0.11 & 0.11 & 0.90 & 0.12 & 0.25 \\
\hline \multirow[t]{3}{*}{ 4th } & ATD & 892 & 903 & 924 & 895 & 911 & 903 & 869 & 807 \\
\hline & Osc & 890 & 900 & 920 & 900 & 910 & 900 & 870 & 805 \\
\hline & $\% \mathrm{Er}$ & 0.22 & 0.33 & 0.43 & 0.56 & 0.11 & 0.33 & 0.11 & 0.25 \\
\hline \multirow[t]{3}{*}{5 th } & ATD & 920 & 887 & 904 & 924 & 913 & 907 & 873 & 792 \\
\hline & Osc & 921 & 890 & 900 & 921 & 910 & 905 & 870 & 790 \\
\hline & $\% \mathrm{Er}$ & 0.11 & 0.34 & 0.44 & 0.33 & 0.33 & 0.22 & 0.34 & 0.25 \\
\hline
\end{tabular}

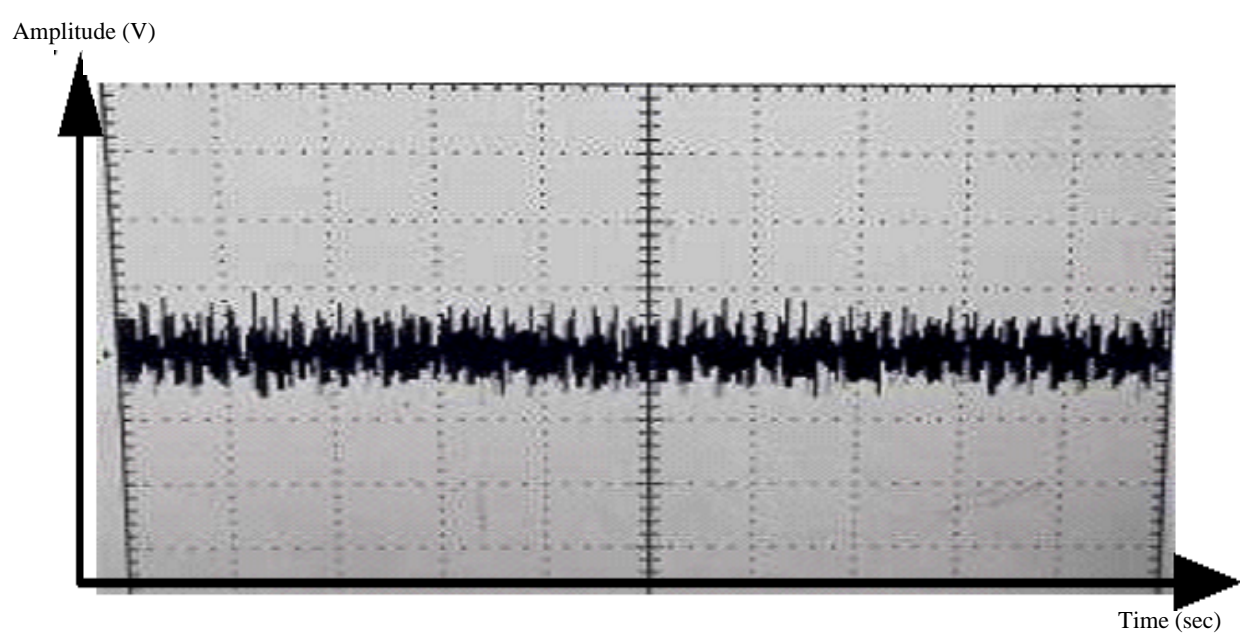

Fig. 10: The oscilloscope display of the pulse sensor output signal when it has not detected the heartbeat

Test of arrythmia monitoring device: The test of the arrhythmia module is done by detecting the output signal which calculated the interval time value (R-R) at 9 detected beats as shown in Fig. 6. Tests conducted on 5 respondents. Each respondent was detected as much as 5 times the measurement. Test results of respondent 1 are shown as Table 2.

Based on Table 2 shows the results of precision testing based on the calculation of Standard deviation
(Stdev) averaging of 13.27. While the results of arrhythmia detection showed data ND (Not Detection) on the five tests.

Table 3 shows the results of the accuracy test based on the measurement of the Arrythmia Telemonitor Device (ATD) that was designed with the result of measurement of R-R signal using Oscilloscope (Osc). Based on the result of measurement to five respondents, the result of the calculation of percentage Error $(\% \mathrm{Er})$ is $0.25 \%$. 


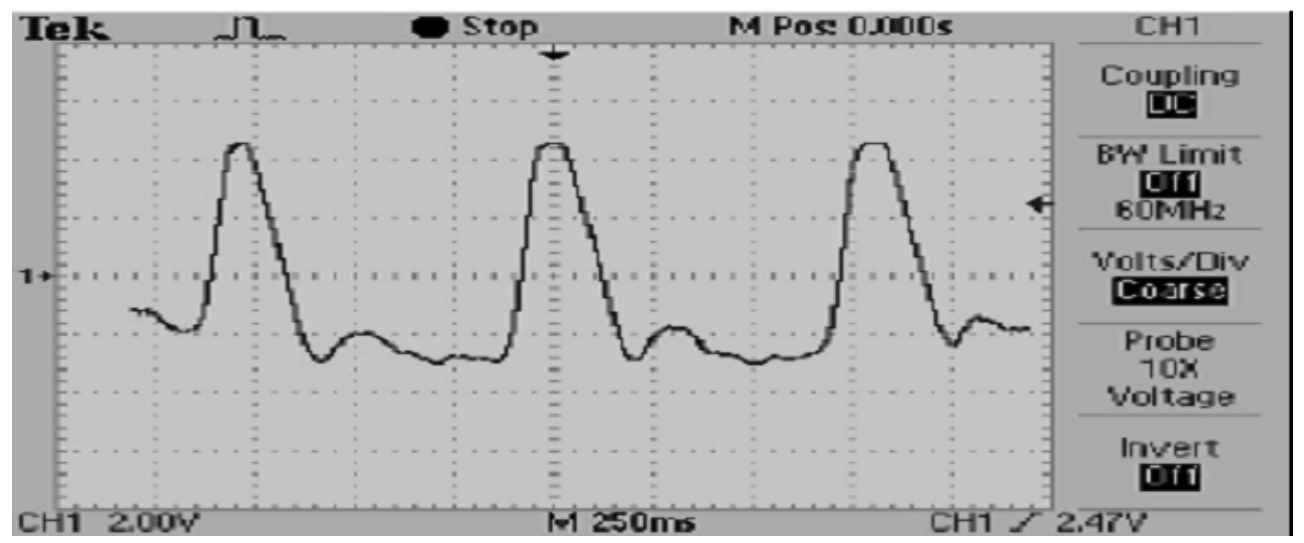

Fig. 11: Oscilloscope display of pulse sensor output signal when detecting heartbeat

\section{CONCLUSION}

This research has successfully designed a cardiac arrhythmia telemonitor device using internet communication whose results can be accessed on a web page with the address http://monitoraritmia.hol.es. The cardiac arrhythmia telemonitor device that has been constructed is composed of input blocks in the form of pulse sensors, keypads and press switches. Process block consisting of Arduino Mega Kit module, Ethernet Shield, router and USB Modem. While the output block consists of a $16 \times 2$ alphanumeric $L C D$ viewer module and a web display accessed using a computer or smartphone device.

Based on test results on five respondents obtained level of accuracy is based on the calculation of procentstase error average of $0.25 \%$. While the results of precision testing based on the calculation Standard deviation (Stdev) averaged 13.27.

\section{ACKNOWLEDGEMENT}

This research was supported by the Research Grant of Kemenristek Dikti Republic of Indoneisa and Gunadarma University in 2017 and 2018.

\section{REFERENCES}

Babiker, S.F., A.L.E. Khair and S.M. Elbasheer, 2011. Microcontroller based heart rate monitor using fingertip sensors. Univ. Khartoum Eng. J., 1: 47-51.
Igasaki, T. and M. Kobayashi, 2017. Measuring cardiorespiratory information in sitting position using multiple piezoelectric sensors. Indonesian J. Electrical Eng. Comput. Sci., 6: 132-138.

Jones, S.A., 2015. ECG Notes: Interpretation and Management Guide. F.A. Davis Company, Philadelphia, Pennsylvania, USA., ISBN: 9780803639300 , Pages: 218.

Kohler, B.U., C. Hennig and R. Orglmeister, 2002. The principles of software QRS detection. IEEE Eng. Med. Biol. Mag., 21: 42-57.

Kusuma, R.W., R.A.A. Abbie and P. Musa, 2016. Design of arrhythmia detection device based on fingertip pulse sensor. Proceedings of the 2nd International Conference on Electrical Systems, Technology and Information (ICESTI'15), April 18, 2016, Springer, Singapore, ISBN:978-981-287-986-8, pp: 363-372.

Tompkins, W.J. and J.G. Webster, 1981. Design of Microcomputer-Based Medical Instrumentation. Prentice Hall, Upper Saddle River, New Jersey, USA., ISBN:9780132012447, Pages: 495.

Zhang, H., G. Lu, S. Li, X. Jing and T. Jiao et al., 2014. A research of non-contact respiration and heartbeat signal separation. Indonesian $\mathrm{J}$. Electr. Eng. Comput. Sci., 12: 3046-3052. 